\title{
Biodistribution and Radiation Dosimetry for a Probe Targeting Prostate-Specific Membrane Antigen for Imaging and Therapy
}

\author{
Ken Herrmann*1,2, Christina Bluemel*1, Martina Weineisen ${ }^{3}$, Margret Schottelius ${ }^{3}$, Hans-Jürgen Wester ${ }^{3,4}$, \\ Johannes Czernin ${ }^{2}$, Uta Eberlein ${ }^{1}$, Seval Beykan ${ }^{1}$, Constantin Lapa ${ }^{1}$, Hubertus Riedmiller ${ }^{5}$, Markus Krebs ${ }^{5}$, \\ Saskia Kropf ${ }^{4}$, Andreas Schirbel ${ }^{1}$, Andreas K. Buck ${ }^{1}$, and Michael Lassmann ${ }^{1}$ \\ ${ }^{1}$ Department of Nuclear Medicine, University Hospital Würzburg, Würzburg, Germany; ${ }^{2}$ Ahmanson Translational Imaging Division, \\ David Geffen School of Medicine at UCLA, Los Angeles, California; ${ }^{3}$ Pharmaceutical Radiochemistry, Technische Universität \\ München, Munich, Germany; ${ }^{4}$ Scintomics GmbH, Fürstenfeldbruck, Germany; and ${ }^{5}$ Department of Urology, University Hospital \\ Würzburg, Würzburg, Germany
}

Prostate-specific membrane antigen (PSMA) is a promising target for diagnosis and treatment of prostate cancer. EuK-Subkff-68 GaDOTAGA ( ${ }^{68} \mathrm{Ga}-\mathrm{PSMA}$ Imaging \& Therapy [PSMA I\&T]) is a recently introduced PET tracer for imaging PSMA expression in vivo. Wholebody distribution and radiation dosimetry of this new probe were evaluated. Methods: Five patients with a history of prostate cancer were injected intravenously with $91-148 \mathrm{MBq}$ of ${ }^{68} \mathrm{Ga}-\mathrm{PSMA}$ I\&T (mean $\pm \mathrm{SD}, 128 \pm 23 \mathrm{MBq}$ ). After an initial series of rapid wholebody scans, 3 static whole-body scans were acquired at 1,2 , and $4 \mathrm{~h}$ after tracer injection. Time-dependent changes of the injected activity per organ were determined. Mean organ-absorbed doses and effective doses were calculated using OLINDA/EXM. Results: Injection of $150 \mathrm{MBq}$ of ${ }^{68} \mathrm{Ga}$-PSMA I\&T resulted in an effective dose of $3.0 \mathrm{mSv}$. The kidneys were the critical organ (33 mGy), followed by the urinary bladder wall and spleen (10 mGy each), salivary glands (9 mGy each), and liver (7 mGy). Conclusion: ${ }^{68} \mathrm{Ga}-\mathrm{PSMA}$ I\&T exhibits a favorable dosimetry, delivering organ doses that are comparable to (kidneys) or lower than those delivered by ${ }^{18} \mathrm{~F}-\mathrm{FDG}$.

Key Words: PET; PSMA; ${ }^{8} \mathrm{Ga}$; dosimetry; prostate cancer

J Nucl Med 2015; 56:855-861

DOI: $10.2967 /$ jnumed.115.156133

$\mathbf{M}$ ore than 220,000 cases of prostate cancer will be diagnosed in 2015 , accounting for $26 \%$ of all new cancer cases in the United States (1). Accurate staging and restaging remain a diagnostic challenge. Visualization of tumor metabolism with PET is gaining increasing interest particularly in the management of patients with biochemical disease relapse (2). Commonly used PET tracers include the glucose analog ${ }^{18} \mathrm{~F}-\mathrm{FDG}$ for imaging the tumor glucose metabolism, especially in dedifferentiated tumors (3); amino acid

Received Feb. 17, 2015; revision accepted Mar. 23, 2015.

For correspondence or reprints contact: Ken Herrmann, Department of Nuclear Medicine, University Hospital Würzburg, Oberdürrbacher Strasse 6, 97080 Würzburg, Germany.

E-mail:Herrmann_K1@ukw.de

${ }^{*}$ Contributed equally to this work.

Published online Apr. 16, 2015.

COPYRIGHT (C 2015 by the Society of Nuclear Medicine and Molecular Imaging, Inc. transport probes such as ${ }^{11} \mathrm{C}$-methionine (4) and the synthetic amino acid probe ${ }^{18} \mathrm{~F}$-1-amino-3-fluorine 18-fluorocyclobutane-1-carboxylicacid (5); as well as probes of lipid metabolism such as choline (6) and acetate (7).

More recently, tracers targeting the prostate-specific membrane antigen (PSMA) have attracted the attention of clinicians and imaging specialists. The overexpression of PSMA in prostate cancer cells (8) is associated with the adverse outcome of prostate cancer patients (9). Glu-NH-CO-NH-Lys-(Ahx)-[ $\left.{ }^{68} \mathrm{Ga}-(\mathrm{HBED}-\mathrm{CC})\right]$ ( ${ }^{68} \mathrm{Ga}$-DKFZ-PSMA-11), a ${ }^{68} \mathrm{Ga}$-labeled PSMA-targeted ligand (10), has been studied by several groups (11-17). More recently, Wester et al. introduced a different PSMA ligand, EuK-Subkff- ${ }^{68} \mathrm{Ga}-$ DOTAGA $\left({ }^{68} \mathrm{Ga}\right.$-PSMA I\&T), that can also be labeled with ${ }^{177} \mathrm{Lu}$ (18) and can thus potentially serve as the therapeutic arm of a new theranostic approach in prostate cancer.

Because the whole-body distribution and dosimetry of ${ }^{68} \mathrm{Ga}$ PSMA I\&T must be determined before its clinical translation, we here report the dynamic biodistribution and dosimetry of this new PET imaging probe in a small cohort of patients with primary or recurrent prostate cancer.

\section{MATERIALS AND METHODS}

\section{Research Design and Subjects}

${ }^{68} \mathrm{Ga}$-PSMA I\&T was administered in compliance with The German Medicinal Products Act, AMG $\S 132 \mathrm{~b}$, and in accordance with the responsible regulatory body (Regierung von [i.e., Government of] Unterfranken). The data analysis was presented to the ethics committee of the Universitätsklinikum Würzburg, and the need for a formal review was waived.

Five patients (age, 59.1-69.9 y; mean age $\pm \mathrm{SD}, 65.1 \pm 4.1$ y) with prostate cancer underwent ${ }^{68} \mathrm{Ga}$-PSMA PET/CT. One patient had biopsyproven primary prostate cancer, 3 had biochemical relapse, and 1 underwent restaging after the start of androgen-deprivation therapy. The mean prostate-specific antigen (PSA) level in the 3 patients with biochemical relapse was $2.9 \pm 3.3 \mathrm{ng} / \mathrm{mL}$, and the time interval between primary diagnosis and biochemical relapse was $2.2 \pm 0.9 \mathrm{y}$. Detailed patient characteristics are presented in Table 1 . Safety was assessed by monitoring adverse events up to $5 \mathrm{~h}$ after administration of ${ }^{68} \mathrm{Ga}$-PSMA I\&T.

\section{Preparation of PSMA-Targeting Probe ${ }^{68} \mathrm{Ga}-\mathrm{PSMA}$ I\&T}

${ }^{68} \mathrm{Ga}$-PSMA I\&T was synthesized using a fully automated, good manufacturing practice-compliant procedure with a GRP module (SCINTOMICS GmbH) connected to a ${ }^{68} \mathrm{Ge} /{ }^{68} \mathrm{Ga}$ generator (Cyclotron 
TABLE 1

Patients' Demographic Data

\begin{tabular}{|c|c|c|c|c|c|c|c|c|c|c|}
\hline $\begin{array}{c}\text { Patient } \\
\text { no. }\end{array}$ & $\begin{array}{l}\text { Age } \\
(y)\end{array}$ & $\begin{array}{l}\text { Height } \\
\text { (cm) }\end{array}$ & $\begin{array}{l}\text { Weight } \\
\text { (kg) }\end{array}$ & $\begin{array}{l}\text { Activity } \\
\text { (MBq) }\end{array}$ & PD & $\begin{array}{c}\text { PET } \\
\text { indication }\end{array}$ & $\begin{array}{c}\text { PSA } \\
\text { level } \\
\text { (ng/mL) }\end{array}$ & $\begin{array}{c}\text { Gleason } \\
\text { Score }\end{array}$ & $\begin{array}{l}\text { Previous } \\
\text { treatment }\end{array}$ & $\begin{array}{c}\text { PET } \\
\text { findings }\end{array}$ \\
\hline 1 & 66.8 & 170 & 74 & 148 & $09 / 12$ & Relapse & 6.7 & 7 & RTx & B \\
\hline 2 & 66.3 & 178 & 95 & 124 & $01 / 13$ & Relapse & 0.5 & 8 & RPT & None \\
\hline 3 & 69.9 & 172 & 81 & 146 & $07 / 14$ & Staging & 101.2 & 7 & - & $\begin{array}{l}\text { Loc, B, } \\
\text { LNs }\end{array}$ \\
\hline 4 & 59.1 & 185 & 110 & 133 & $07 / 11$ & Relapse & 1.6 & 8 & $\begin{array}{l}\text { RPT and } \\
\text { RTx }\end{array}$ & LNs \\
\hline 5 & 63.5 & 177 & 70 & 91 & $07 / 14$ & $\begin{array}{l}\text { Follow- } \\
\text { up }\end{array}$ & 1.4 & 8 & ADT & B, Loc \\
\hline
\end{tabular}

$\mathrm{PD}=$ primary diagnosis; $\mathrm{RTx}=$ radiotherapy; $\mathrm{B}=$ bone metastasis; $\mathrm{RPT}$ = radical prostatectomy; Loc = tumor tissue in the prostate; $\mathrm{LN}=$ lymph node metastasis; ADT = androgen-deprivation therapy.

Co. Ltd.) and equipped with a disposable single-use cassette kit (ABX). A standardized labeling sequence with $40 \mu \mathrm{g}$ of unlabeled PSMA I\&T (SCINTOMICS GmbH) was used as previously described (19).

Before application, the radiopharmaceuticals were analyzed according to the monographs 2462 (Gallium Chloride) and 2482 (Gallium Edotreotide) of the European Pharmacopoeia by analytic high-performance liquid chromatography. Analytic high-performance liquid chromatography was performed on a SCINTOMICS system equipped with a RP-18 column (Nucleosil, $125 \times 4.6 \mathrm{~mm}$; CS-Chromatographie). The eluent had a linear gradient from $100 \%$ water $(0.1 \%$ trifluoroacetic acid) to $100 \% \mathrm{MeCN}$ ( $0.1 \%$ trifluoroacetic acid) over $20 \mathrm{~min}$. The radiochemical purity of the tracer was determined with a miniGITA thin-layer chromatography scanner (Raytest) using Varian silica gel-impregnated glass fiber sheets and $0.1 \mathrm{M}$ sodium citrate as eluent.

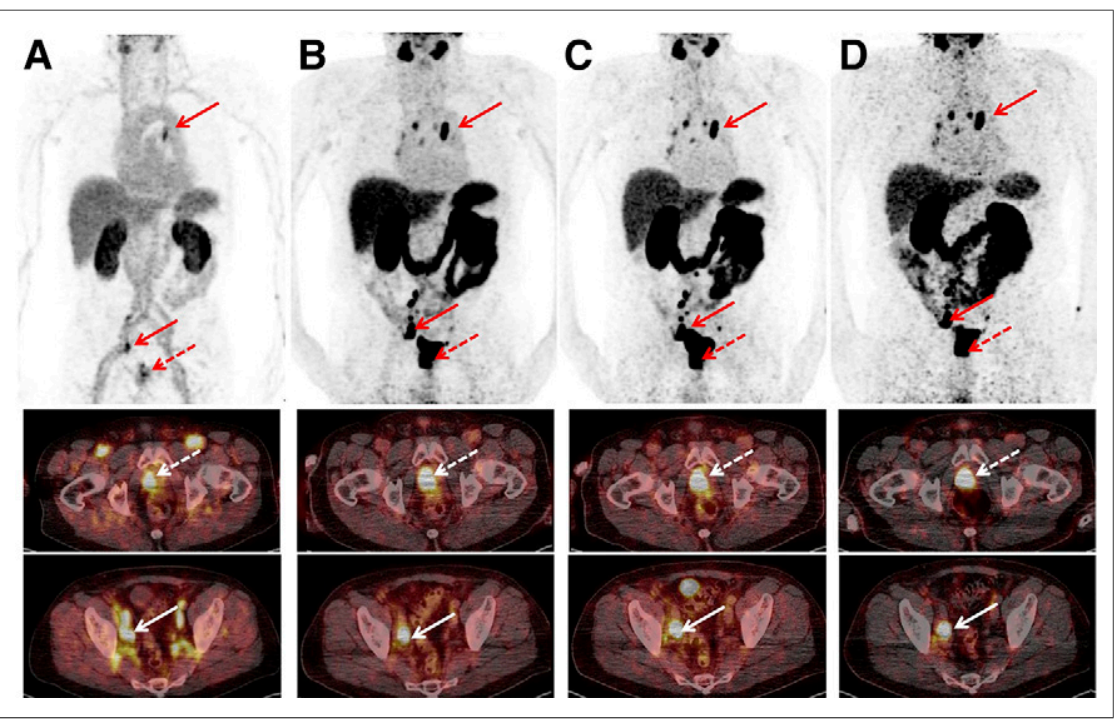

FIGURE 1. Sequential scan of 70-y-old patient (P3; PSA level, $101.2 \mathrm{ng} / \mathrm{mL}$ ) with initial diagnosis of prostate cancer (dotted arrow) showing high tumor-to-background ratio. Maximumintensity projections (upper row) and axial slices (middle and lower rows) at different time points are displayed ([A] early rapid scan, [B] 1-h scan, [C] 2-h scan, [D] 4-h scan). Primary prostate cancer (middle row; 1-h SUV max $_{1}, 55.0$ ) as well as numerous iliacal (lower row; 1-h SUV $\max , 57.0$ ) and mediastinal lymph node metastases (upper row; 1-h SUV $\max , 31.4$ ) can be depicted immediately after injection and up to $4 \mathrm{~h}$.

\section{PET Imaging}

All ${ }^{68}$ Ga-PSMA I\&T scans were obtained on a dedicated PET/CT scanner (Biograph mCT 64; Siemens Medical Solutions) after at least $4 \mathrm{~h}$ of fasting. Low-dose CT scans for attenuation correction were acquired $(35 \mathrm{mAs}, 120 \mathrm{keV}$, a $512 \times 512$ matrix, 5 -mm slice thickness with a total of 201 slices, increment of $30 \mathrm{~mm} / \mathrm{s}$, rotation time of $0.5 \mathrm{~s}$, and pitch of 0.8). The imaging field ranged from the head (patient 1; [P1]) or the base of the skull (patients 2-5 [P2-5]) to the proximal thighs. Immediately after injection, the PET imaging sequences started with a series of 3 (P1) or 4 (P2-5) 300-s whole-body scans.

Subsequently, 3 static whole-body scans encompassing 6-7 bed positions were acquired at 1,2 , and $4 \mathrm{~h}$ after tracer injection. All data were decay-corrected to the starting time of each individual scan. All PET images were corrected for photon attenuation, dead-time, random events, and scatter. The PET scanner is periodically checked for calibration accuracy as part of quality control according to published guidelines (20) and is accredited by European Association of Nuclear Medicine Research Ltd.

\section{Imaging and Dosimetry}

All images were analyzed qualitatively by experienced nuclear physicians for the presence of suggestive lesions. To determine the time point providing the best sensitivity and optimal lesion-to-background contrast, we first examined all available datasets to identify target lesions.

Semiquantitative analysis of visually detectable lesions was done by 3-dimensional volumes of interest (VOIs). Corresponding maximum standardized uptake values $\left(\mathrm{SUV}_{\mathrm{max}}\right)$ were recorded as a function of time. The European Association of Nuclear Medicine recommendations for good dosimetry reporting were used (21).

Full organ segmentation was performed by a single observer on CT images and PET images for all segmentable organs (e.g., gallbladder, heart, kidneys, spleen, liver, salivary glands, and bladder) and lesions using the E.SOFT software VA60C (Siemens Medical Solutions). A whole-body VOI was also drawn. Bone marrow 


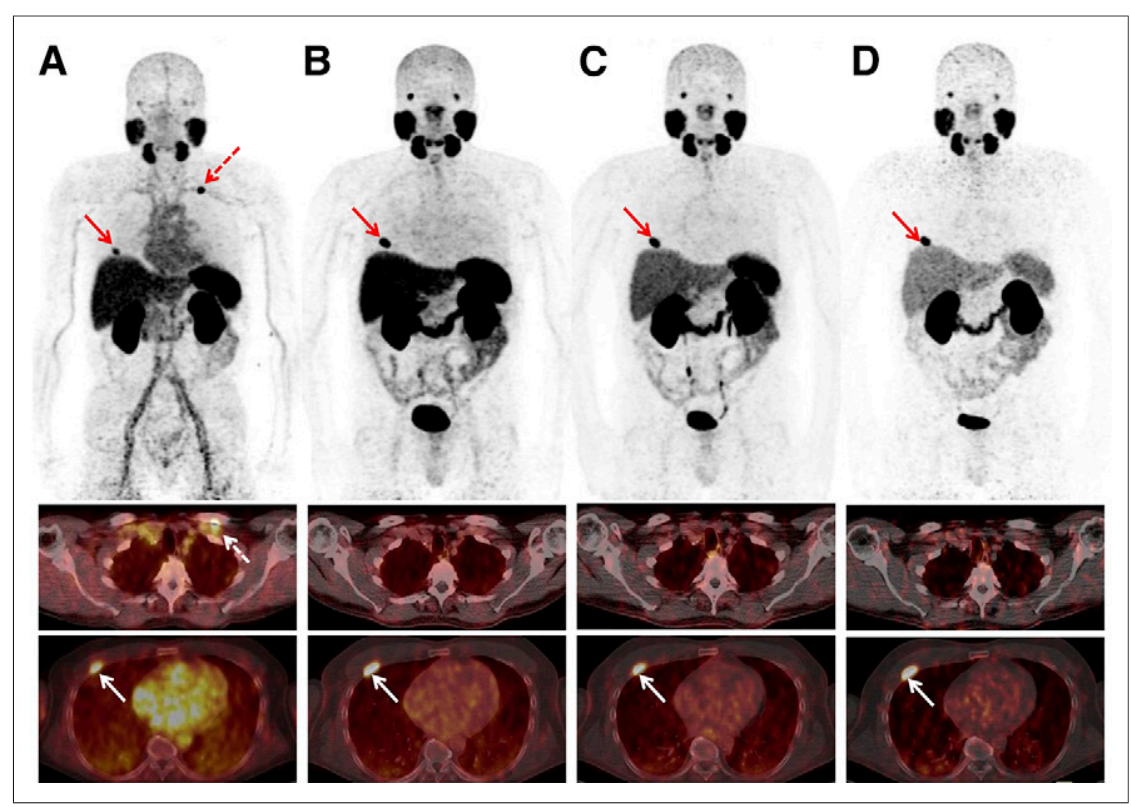

FIGURE 2. Sequential patient scan (P1) of 67-y-old patient with biochemical relapse (PSA level, $6.7 \mathrm{ng} / \mathrm{mL}$ ) $1.8 \mathrm{y}$ after curative radiotherapy. Maximum-intensity projections (upper row) and axial

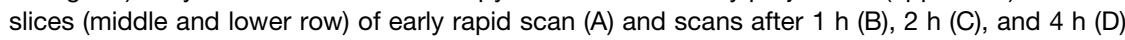
show increased uptake in rib metastasis (A-D, arrows) and physiologic uptake in lacrimal glands, salivary glands, liver, spleen, kidneys, and slightly in bowel (A-D). Red dotted arrow in A depicts unspecific uptake in left subclavian vein.

dosimetry was derived from CT-based VOIs placed over lumbar vertebrae $2-4$. From the coregistered PET images, average organ activity per volume in $\mathrm{kBq} / \mathrm{mL}$ was obtained for each frame. The total activity in the respective VOI was calculated subsequently by multiplying the average organ activity per volume with the respective volume taken from the CT images. Because the scanning was done only from the head or base of the skull to the mid thigh, the total activity in the whole body (measured portions and the nonmeasured portions of the lower extremities and the head) was estimated by extrapolating the respective whole-body time-activity curves to the injection time and by calculating a corresponding scaling factor. This scaling factor was applied to all whole-body measurements of the same patient for calculating the timeintegrated activity coefficients. All measured organ activities were normalized to the respective total injected activities.

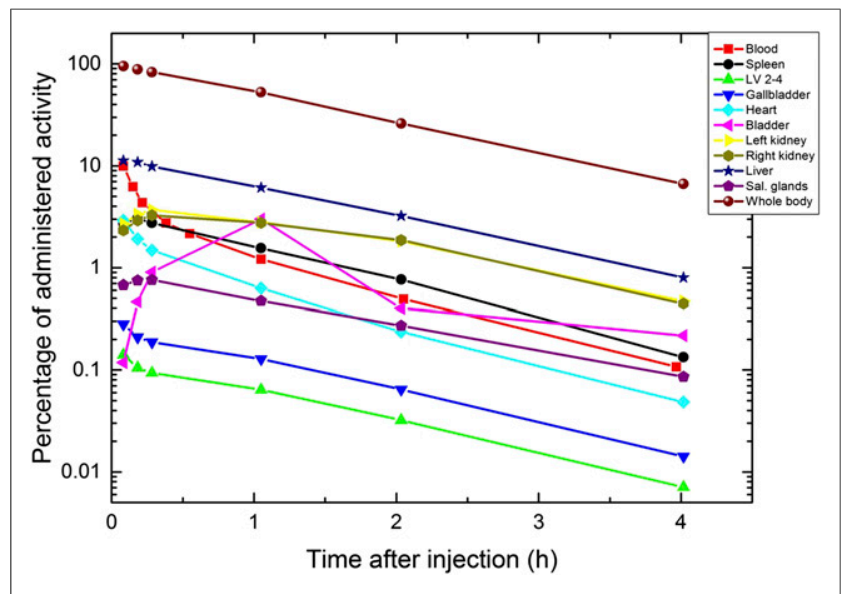

FIGURE 3. Time-activity curves for P1 for all organs showing uptake, for whole body, and for blood. For blood, percentage of activity is given per liter of blood.
The integration of time-activity curves was performed using the software NUKFIT (22). For this investigation, a systematic error in activity quantification of $10 \%$ was assumed. The time-activity curves of the urinary bladder contents were integrated using a trapezoidal integration and assuming physical decay after the last data point.

To assess differences in bone marrow timeintegrated activity coefficients while applying different methods, the time-integrated activity coefficient for the bone marrow was derived from 2 methods proposed by Ferrer et al. for radioimmunotherapy (23). Particularly for the blood-based method it is not conclusively proven which red marrow-to-blood ratio (RMBLR) is optimal. For [ ${ }^{177} \mathrm{Lu}$-DOTA0,Tyr3] octreotate, the activity in bone marrow aspirates correlates with the activity measured in blood (24), suggesting a RMBLR of 1 . For ${ }^{68} \mathrm{Ga}$-PSMA I\&T, no such data are available. As, in a previous study with ${ }^{68} \mathrm{Ga}$-pentixafor (25), the agreement between the image-based method and the bloodbased method was better when the RMBLR for radioimmunotherapy was applied, we decided to apply the same method for this compound.

The individual time-integrated activity coefficients were used for calculating effective doses for the standard $70-\mathrm{kg}$ adult male model using OLINDA/EXM (26) for each patient separately. Entering the mean values of the time-integrated activity coefficients into OLINDA/EXM provided organ-absorbed doses and effective doses (based on tissue-weighting factors from International Commission on Radiological Protection [ICRP] publication 60 (27)) for a standard patient. The lesion-absorbed doses for the salivary glands were calculated from the corresponding time-integrated activity coefficients with the OLINDA/EXM unit density sphere model for each of the glands separately, taking into account the individual gland volume. The resulting absorbed doses were averaged to obtain a mean absorbed dose. This model better represents more closely the real energy deposition pattern assuming that the energy is deposited in a uniform sphere of $85 \mathrm{~g}$, which represents the salivary glands according to ICRP 89 (28). SDs were calculated using Excel (Microsoft).

In addition, the effective dose according to ICRP 103 (29) has been calculated despite the fact that the organ-absorbed dose rates per unit activity values for radiopharmaceuticals based on the latest ICRP voxel phantoms in ICRP 110 (30) have not been published yet (31). As there was no female patient, a sex-specific calculation has not been performed.

\section{RESULTS}

\section{Radioligand and Patients}

The administered amount of ${ }^{68} \mathrm{Ga}$-PSMA I\&T was less than $20 \mu \mathrm{g}$. The overall injected activity (radiochemical purity $>98 \%$ ) ranged from 91 to $148 \mathrm{MBq}$ (mean $\pm \mathrm{SD}, 128 \pm 23 \mathrm{MBq}$ ) with a specific activity greater than $5 \mathrm{MBq} / \mu \mathrm{g}$. Activity remaining in the injection syringe was quantified and considered. Injection of ${ }^{68} \mathrm{Ga}$-PSMA I\&T was well tolerated by all subjects. No side effects or changes in vital signs were observed during the study.

\section{Biodistribution}

On qualitative image analysis, all but 1 patient (P2; PSA value, $0.5 \mathrm{ng} / \mathrm{mL}$ ) presented suggestive focal lesions. The patient with 


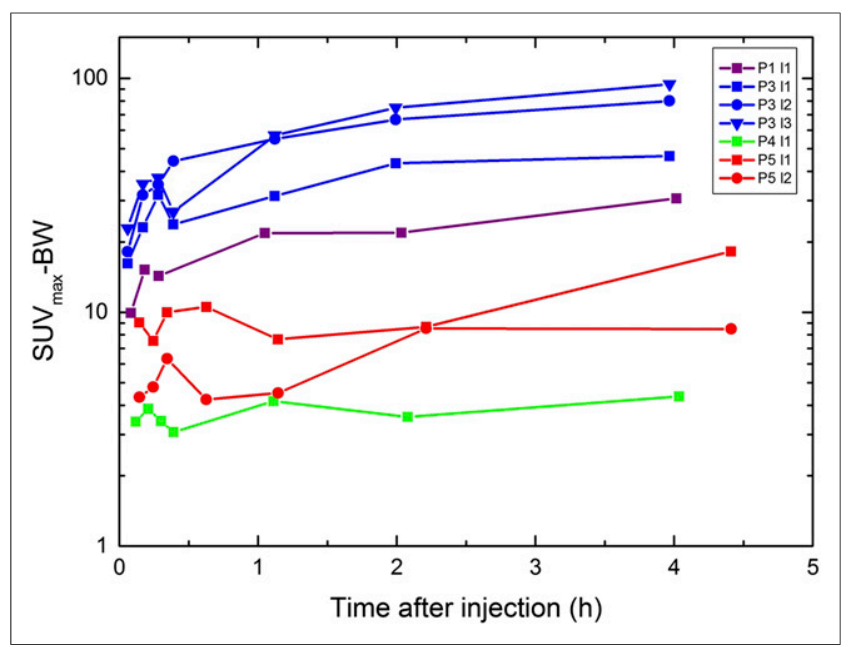

FIGURE 4. Temporal variation of $S_{\text {S }} V_{\max }$-body weight in visible lesions in P1 (red), P3 (light blue), P4 (green), and P5 (blue). P1-11 = bone lesion; P3-I1 = lymph node mediastinal; P3-12 = tumor tissue prostate; P3-13 = Iymph node iliacal; P4-14 = lymph node; P5-I1 = tumor tissue prostate; P5-12 = bone lesion.

biopsy-proven but untreated prostate cancer (P3; PSA value, 101.2 $\mathrm{ng} / \mathrm{mL}$ ) presented increased uptake in the prostate, mediastinal and iliac lymph nodes, and lumbar spine (Fig. 1). In the patient recently started on androgen ablation therapy, tracer uptake was observed in the prostate as well as in the lumbar spine lesions (P5). In 2 patients with biochemical recurrence (PSA values, 1.6 and 6.7 $\mathrm{ng} / \mathrm{mL}$ ), pathologic tracer uptake was identified in a rib lesion (P1) and an iliac lymph node (P4), respectively (Table 1).

The biodistribution of ${ }^{68} \mathrm{Ga}$-PSMA I\&T was determined for all major organs in all patients. Figures 1 and 2 depict whole-body maximum-intensity-projection images of 2 subjects (P1 and P3) at different time points. Figure 3 shows the time-activity curves for various organs and the blood (per liter of blood) expressed as percentage injected activity for the same patient as in Figure 2 (P1).

The highest uptake in any organ was observed in the liver of patient 5 , with $13.3 \%$ of the injected activity after $5 \mathrm{~min}$. The data at later time points for this patient showed a rapid washout phase, with an uptake of less than $0.8 \%$ after $4 \mathrm{~h}$. For all patients the mean maximal liver uptake was $10.6 \% \pm 1.7 \%$. The mean uptake in the kidneys of all patients varied between $3.2 \% \pm 0.6 \%$ and $0.3 \% \pm 0.2 \%$ about $20 \mathrm{~min}$ and $4 \mathrm{~h}$ after administration, respectively. Significant tracer uptake was also observed in the heart, with a mean uptake of $2.5 \% \pm 0.6 \%$ after $5 \mathrm{~min}$, declining to less than $0.1 \%$ after $4 \mathrm{~h}$.

The gallbladder exhibited low uptake, compared with other organs. The highest uptake in the urinary bladder before voiding $(5.6 \%)$ was observed in P4. All other patients showed bladder uptake of less than $5 \%$ of the injected activity. All patients voided for the first time 40-60 min after administration of the radioligand. Comparable time-activity curves were recorded in all other patients.

\section{Image Analysis}

Immediately after injection there was only minimal urinary bladder activity. Thus, uptake in the prostate or prostate bed is least affected by activity spillover (Figs. 1 and 2). However, lymph node metastases adjacent to blood vessels can be detected better on later images because of the high blood-pool activity at early time points. For the remainder of the body, image acquisition after $1 \mathrm{~h}$ provided excellent image contrast.

$\mathrm{SUV}_{\text {max }}$ increased in all but 1 lesion from early to late imaging (Fig. 4), but the visual impression was better after $1 \mathrm{~h}$. The $\mathrm{SUV}_{\max }$ for $\mathrm{P} 4$, derived from subcentimeter lymph nodes prone to partialvolume effects, was found at $1 \mathrm{~h}$. In none of the lesions was there a washout observed until the last scanning time point.

TABLE 2

Time-Integrated Activity Coefficients

\begin{tabular}{|c|c|c|c|c|c|c|c|}
\hline \multirow[b]{2}{*}{ Source organ } & \multicolumn{7}{|c|}{ Time-integrated activity coefficients (h) } \\
\hline & P1 & $\mathrm{P} 2$ & P3 & P4 & P5 & Mean & SD \\
\hline Remainder & 1.023 & 1.029 & 0.952 & 1.098 & 0.964 & 1.013 & 0.059 \\
\hline Liver & 0.181 & 0.141 & 0.100 & 0.142 & 0.173 & 0.147 & 0.032 \\
\hline Right kidney & 0.080 & 0.068 & 0.075 & 0.078 & 0.038 & 0.068 & 0.018 \\
\hline Left kidney & 0.084 & 0.076 & 0.087 & 0.073 & 0.042 & 0.073 & 0.018 \\
\hline Kidneys, sum & 0.164 & 0.144 & 0.163 & 0.151 & 0.080 & 0.140 & 0.035 \\
\hline Heart & 0.021 & 0.018 & 0.015 & 0.024 & 0.017 & 0.019 & 0.003 \\
\hline Bladder contents & 0.042 & 0.029 & 0.055 & 0.039 & 0.088 & 0.051 & 0.023 \\
\hline Gallbladder & 0.002 & 0.001 & 0.001 & 0.002 & 0.002 & 0.002 & 0.001 \\
\hline Spleen & 0.042 & 0.010 & 0.011 & 0.019 & 0.032 & 0.023 & 0.014 \\
\hline Parotid glands & 0.010 & & 0.004 & & 0.005 & 0.006 & 0.003 \\
\hline Submandibular glands & 0.005 & 0.003 & 0.004 & 0.002 & 0.003 & 0.004 & 0.001 \\
\hline LV2-4 & 0.002 & 0.001 & 0.001 & 0.001 & 0.001 & 0.001 & 0.000 \\
\hline Red marrow lumbar vertebrae & 0.027 & 0.013 & 0.009 & 0.018 & 0.016 & 0.017 & 0.007 \\
\hline Red marrow blood & 0.028 & 0.026 & 0.019 & 0.024 & 0.022 & 0.024 & 0.003 \\
\hline
\end{tabular}

Calculation methods for red marrow lumbar vertebrae and red marrow blood are presented in "Material and Methods" section. $\mathrm{P}=$ patient; LV2-4 = lumbar vertebrae 2-4. 
TABLE 3

Absorbed Organ Dose Coefficients and Absorbed Organ Doses (150 MBq of ${ }^{68} \mathrm{Ga}-\mathrm{PSMA}$ )

\begin{tabular}{|c|c|c|c|c|}
\hline Target organ & $\beta$ (mGy/MBq) & Photon (mGy/MBq) & Total (mGy/MBq) & $\begin{array}{c}\text { Absorbed dose (mGy) } \\
(150 \mathrm{MBq})\end{array}$ \\
\hline Adrenals & $5.87 \mathrm{E}-03$ & $7.62 \mathrm{E}-03$ & $1.35 \mathrm{E}-02$ & 2.0 \\
\hline Brain & $5.87 \mathrm{E}-03$ & $2.43 \mathrm{E}-03$ & $8.29 \mathrm{E}-03$ & 1.2 \\
\hline Breasts & $5.87 \mathrm{E}-03$ & $2.58 \mathrm{E}-03$ & $8.44 \mathrm{E}-03$ & 1.3 \\
\hline Gallbladder wall & $1.16 \mathrm{E}-02$ & $7.99 \mathrm{E}-03$ & $1.96 \mathrm{E}-02$ & 2.9 \\
\hline Lower large intestine wall & $5.87 \mathrm{E}-03$ & $4.68 \mathrm{E}-03$ & $1.06 \mathrm{E}-02$ & 1.6 \\
\hline Small intestine & $5.87 \mathrm{E}-03$ & $5.24 \mathrm{E}-03$ & $1.11 \mathrm{E}-02$ & 1.7 \\
\hline Stomach wall & 5.87E-03 & $5.24 \mathrm{E}-03$ & $1.11 \mathrm{E}-02$ & 1.7 \\
\hline Upper large intestine wall & $5.87 \mathrm{E}-03$ & $5.25 \mathrm{E}-03$ & $1.11 \mathrm{E}-02$ & 1.7 \\
\hline Heart wall & $1.48 \mathrm{E}-02$ & $5.36 \mathrm{E}-03$ & $2.02 \mathrm{E}-02$ & 3.0 \\
\hline Kidneys & $1.96 \mathrm{E}-01$ & $2.31 \mathrm{E}-02$ & $2.20 \mathrm{E}-01$ & 33.0 \\
\hline Liver & 3.30E-02 & $1.01 \mathrm{E}-02$ & 4.31E-02 & 6.5 \\
\hline Lungs & $5.87 \mathrm{E}-03$ & 3.91E-03 & $9.78 \mathrm{E}-03$ & 1.5 \\
\hline Muscle & $5.87 \mathrm{E}-03$ & 3.65E-03 & $9.52 \mathrm{E}-03$ & 1.4 \\
\hline Ovaries & $5.87 \mathrm{E}-03$ & 4.94E-03 & $1.08 \mathrm{E}-02$ & 1.6 \\
\hline Pancreas & 5.87E-03 & $7.38 \mathrm{E}-03$ & 1.32E-02 & 2.0 \\
\hline Red marrow & 8.07E-03 & 4.35E-03 & $1.24 \mathrm{E}-02$ & 1.9 \\
\hline Osteogenic cells & 1.16E-02 & 4.04E-03 & 1.57E-02 & 2.4 \\
\hline Skin & 5.87E-03 & $2.28 \mathrm{E}-03$ & $8.15 \mathrm{E}-03$ & 1.2 \\
\hline Spleen & $5.26 \mathrm{E}-02$ & $1.09 \mathrm{E}-02$ & 6.34E-02 & 9.5 \\
\hline Testes & 5.87E-03 & $3.28 \mathrm{E}-03$ & $9.14 \mathrm{E}-03$ & 1.4 \\
\hline Thymus & $5.87 \mathrm{E}-03$ & $3.62 \mathrm{E}-03$ & $9.49 \mathrm{E}-03$ & 1.4 \\
\hline Thyroid & $5.87 \mathrm{E}-03$ & $3.15 \mathrm{E}-03$ & $9.01 \mathrm{E}-03$ & 1.4 \\
\hline Urinary bladder wall & 5.70E-02 & 1.03E-02 & 6.74E-02 & 10.1 \\
\hline Uterus & $5.87 \mathrm{E}-03$ & $5.72 \mathrm{E}-03$ & $1.16 \mathrm{E}-02$ & 1.7 \\
\hline Salivary glands & 6.07E-02 & - & 6.07E-02 & 9.1 \\
\hline Total body & $7.88 \mathrm{E}-03$ & $3.85 \mathrm{E}-03$ & 1.17E-02 & 1.8 \\
\hline Effective dose coefficient (mSv/MBq) & & & 1.99E-02 & \\
\hline Effective dose coefficient $(\mathrm{mSv} / \mathrm{MBq})^{*}$ & & & 1.93E-02 $\pm 0.09 \mathrm{E}-02$ & \\
\hline Effective dose (mSv) & & & & 3.0 \\
\hline
\end{tabular}

For assessing quantitatively the optimal time point for scanning the relative uptake ratios of the lesion activity to the activity in the whole body was assessed for the time points $30 \mathrm{~min}, 1 \mathrm{~h}$, and $2 \mathrm{~h}$ after administration and was highest after $2 \mathrm{~h}$ (mean uptake ratios for all lesions compared with $\mathrm{t}=30 \mathrm{~min}, 1: 1.4: 1.9)$.

Because the lesion volumes were small $(<3 \mathrm{~mL})$, absorbed doses were not calculated for these lesions as there is no reliable method for determining the uptake in these volumes due to the partial-volume effect. Data on the partial-volume effect for ${ }^{68} \mathrm{Ga}$ and small volumes are shown by, for example, Preylowski et al. (32).

\section{Dosimetry}

Time-integrated activity coefficients of segmented organs were calculated for each patient individually. In addition, the mean values for all patients are given (Table 2). All corresponding errors for calculating the individual time-activity curves were less than
$5 \%$. The corresponding values are not shown in Table 2 as they were much smaller than the SD when comparing all patients (Table 2, column 7). Therefore, all errors were neglected for the calculation of the mean absorbed organ doses.

The highest number of disintegrations per organ occurred in the liver and kidneys, with an average time-integrated activity coefficient of $0.15 \mathrm{~h}$ (liver) and $0.14 \mathrm{~h}$ (kidneys). The average absorbed dose/ dose coefficients across all subjects are shown in Table 3 ( \pm SD). The highest absorbed dose per unit activity was observed in the kidneys $(2.20 \mathrm{E}-01 \mathrm{mGy} / \mathrm{MBq})$, followed by the urinary bladder wall (6.7E-02 mGy/MBq), spleen (6.3E-02 mGy/MBq), salivary glands (6.1E-02 mGy/MBq), and liver (4.3E-02 mGy/MBq).

The average effective doses reported individually for each patient with the tissue-weighting factors from ICRP publication 60 (27) was $1.99 \mathrm{E}-02 \pm 0.09 \mathrm{E}-02 \mathrm{mSv} / \mathrm{MBq}$. The SD of the effective dose was calculated by taking the mean of the individual 
TABLE 4

Comparison of Absorbed Dose Coefficients and Absorbed Doses for Several Prostate-Specific Compounds

\begin{tabular}{|c|c|c|c|c|c|c|c|c|c|}
\hline & & ${ }^{124}$ I-PSMA & $\begin{array}{c}\text { 123/-MIP- } \\
1072\end{array}$ & $\begin{array}{c}\text { 123/-MIP- } \\
1095\end{array}$ & Pentixafor & DOTATOC & DOTATATE & ${ }^{18} \mathrm{~F}-\mathrm{FDG}$ & PSMA-IT \\
\hline Target organ & Unit & $\begin{array}{l}\text { Zechmann } \\
\text { (33) }\end{array}$ & $\begin{array}{c}\text { Barrett } \\
(36)\end{array}$ & $\begin{array}{c}\text { Barrett } \\
(36)\end{array}$ & $\begin{array}{l}\text { Herrmann } \\
\text { (25) }\end{array}$ & $\begin{array}{c}\text { Sandstrom } \\
\text { (34) }\end{array}$ & $\begin{array}{c}\text { Sandstrom } \\
\text { (34) }\end{array}$ & $\begin{array}{c}\text { ICRP } 106 \\
(35)\end{array}$ & This work \\
\hline Kidneys & $\begin{array}{l}\mathrm{mSv} / \\
\mathrm{MBq}\end{array}$ & $1.39 \mathrm{E}+00$ & $5.4 \mathrm{E}-02$ & 1.10E-2 & $3.50 \mathrm{E}-02$ & 8.20E-02 & 9.30E-02 & $1.70 \mathrm{E}-02$ & $2.20 \mathrm{E}-01$ \\
\hline Liver & $\begin{array}{l}\mathrm{mSv} / \\
\mathrm{MBq}\end{array}$ & $1.66 \mathrm{E}-00$ & $2.4 \mathrm{E}-02$ & $5.8 \mathrm{E}-2$ & $1.75 \mathrm{E}-02$ & 4.10E-02 & $5.00 \mathrm{E}-02$ & $2.10 \mathrm{E}-02$ & 4.31E-02 \\
\hline Spleen & $\begin{array}{l}\mathrm{mSv} / \\
\mathrm{MBq}\end{array}$ & 7.7E-01 & 2.3E-2 & 4.7E-2 & $5.38 \mathrm{E}-02$ & $1.08 \mathrm{E}-01$ & $1.09 \mathrm{E}-01$ & $1.10 \mathrm{E}-02$ & $6.34 \mathrm{E}-02$ \\
\hline Urinary bladder wall & $\begin{array}{l}\mathrm{mSv} / \\
\mathrm{MBq}\end{array}$ & 5.7E-01 & $9.2 \mathrm{E}-2$ & $2.1 \mathrm{E}-2$ & $8.14 \mathrm{E}-02$ & $1.19 \mathrm{E}-01$ & $9.80 \mathrm{E}-02$ & $1.30 \mathrm{E}-01$ & $6.74 \mathrm{E}-02$ \\
\hline $\begin{array}{c}\text { Effective dose } \\
\text { coefficient }\end{array}$ & $\begin{array}{l}\mathrm{mSv} / \\
\mathrm{MBq}\end{array}$ & $5.8 \mathrm{E}-01$ & $2.5 \mathrm{E}-2$ & 3.2E-2 & $1.56 \mathrm{E}-02$ & 2.10E-02 & 2.10E-02 & $1.90 \mathrm{E}-02$ & 1.99E-02 \\
\hline $\begin{array}{l}\text { Typical injected } \\
\text { activity }\end{array}$ & $\mathrm{MBq}$ & 67 & 370 & 370 & 150 & 185 & 150 & 370 & 150 \\
\hline Effective dose & $\mathrm{mSv}$ & 38.9 & 9.3 & 11.8 & 2.3 & 3.9 & 3.2 & 7.0 & 3.0 \\
\hline
\end{tabular}

patients' effective doses. The effective dose when the mean timeintegrated activity coefficients were used resulted in a value of $1.99 \mathrm{E}-02 \mathrm{mSv} / \mathrm{MBq}$ (Table 3). Both values agreed well. The effective dose for an injection of $150 \mathrm{MBq}$ of ${ }^{68} \mathrm{Ga}$-PSMA I\&T was $3.0 \mathrm{mSv}$. The effective dose coefficient using ICRP 103 (29) tissue-weighting factors for the standard patient was $1.57 \mathrm{E}-02 \mathrm{mSv} / \mathrm{MBq}$.

\section{DISCUSSION}

${ }^{68} \mathrm{Ga}$-PSMA I\&T shows a favorable dosimetry and biodistribution in prostate cancer patients. Its dosimetry compares favorably with that of other novel prostate cancer-specific imaging probes labeled with ${ }^{68} \mathrm{Ga},{ }^{123} \mathrm{I}$, or ${ }^{124} \mathrm{I}(33-36)$ (Table 4). In addition, values for ${ }^{68} \mathrm{Ga}$-labeled pentixafor (25), DOTATOC, and DOTATATE (34) and for ${ }^{18} \mathrm{~F}-\mathrm{FDG}$ (35) are provided for comparison. Although the highest lesion-to-background ratio was observed $2 \mathrm{~h}$ after administration of the radiopharmaceutical, we recommend, for practical reasons and because the lesion-to-background ratio is also acceptable, scanning the patients at $1 \mathrm{~h}$ after administration of ${ }^{68} \mathrm{Ga}$-PSMA I\&T.

Several theranostic PET probes of PSMA expression have been developed recently. The dosimetry of a ${ }^{124} \mathrm{I}$ - and ${ }^{123} \mathrm{I}$-labeled smallmolecule inhibitors of PSMA has been recently reported (MIP-1095, MIP-1072) (33,36). The kidney-absorbed dose coefficients for ${ }^{68} \mathrm{Ga}-$ PSMA I\&T are higher than for other ${ }^{68} \mathrm{Ga}$ - and ${ }^{123} \mathrm{I}$-labeled compounds but much lower than that of ${ }^{124} \mathrm{I}-\mathrm{MIP}-1095$. As for ${ }^{124} \mathrm{I}-\mathrm{MIP}-$ 1095 , high physiologic uptake was observed in the salivary glands for ${ }^{68} \mathrm{Ga}$-PSMA I\&T. Both organs could be at risk and might need to be considered when developing ${ }^{177} \mathrm{Lu}$-labeled PSMA I\&T as a clinical theranostic. The effective dose is highest for the ${ }^{124} \mathrm{I}$ - and ${ }^{123} \mathrm{I}$-labeled small-molecule inhibitors of PSMA for their respective administered activities (39, 12, and $9 \mathrm{mSv}$, Table 4).

Regarding methodologic considerations, the mean timeintegrated activity coefficient is higher when using the blood-based method for bone marrow dosimetry as compared with the imagebased method. Although this notion conflicts with the observations of Ferrer's report (23), we decided to assess the absorbed bone marrow dose conservatively using the higher values of the bloodbased method. Overall, the absorbed doses to the bone marrow in our group of patients are of the order of several mGy for an administered activity of $150 \mathrm{MBq}$, thus showing that the bone marrow is not an organ at risk.

The urinary excretion does not rely on model assumptions. In fact, the current data were obtained after an observation period of at least $4 \mathrm{~h}$ after injection. At this time, $4 \%-7 \%$ of the injected activity was still retained in the whole-body. A comparison of the time-integrated activity coefficients of the bladder contents to the activity in the remainder of the body shows that, as a conservative estimate, less than $10 \%$ of the injected activity was excreted through the urinary tract. Thus, the absorbed dose to the bladder wall from $150 \mathrm{MBq}$ of ${ }^{68} \mathrm{Ga}$-PSMA I\&T is significantly lower than that from an injection of $370 \mathrm{MBq}$ of ${ }^{18} \mathrm{~F}-\mathrm{FDG}(31)$.

As expected, ${ }^{68} \mathrm{Ga}$-PSMA I\&T was well tolerated by all patients. No acute or subacute adverse events were observed, and no significant changes in total blood count, kidney, or hepatic function occurred.

${ }^{68}$ Ga-labeled PSMA-targeted radioligands (10) allow the in vivo visualization of PSMA expression. Because PSMA expression is associated with an adverse prognosis, this probe may provide important phenotypic in addition to the diagnostic information.

The high tumor-to-background ratios and the favorable biodistribution have resulted in rapid clinical adoption in several centers (11-17). In addition, initial therapeutic attempts with ${ }^{131}$ I-labeled PSMA ligands have been reported (33). However, ${ }^{68} \mathrm{Ga}$-PSMA I\&T allows for the labeling with ${ }^{177} \mathrm{Lu}(18)$, which is a potentially more desirable therapeutic compound (18).

In 4 of the 5 scans, pathologic tracer uptake consistent with malignant disease was observed. The 1 negative scan was found in a patient with biochemical relapse and a low PSA level of $0.5 \mathrm{ng} / \mathrm{mL}$. Metabolic PET probes such as ${ }^{11} \mathrm{C}$ - or ${ }^{18} \mathrm{~F}$-choline and ${ }^{11} \mathrm{C}$-acetate also failed to detect sites of recurrence in patients with low serum PSA levels. The potential strength of ${ }^{68} \mathrm{Ga}$-PSMA I\&T is its ability to serve as a predictive biomarker for response to its ${ }^{177} \mathrm{Lu}$-labeled therapeutic analogs. This theranostic concept has been highly successful in the context of somatostatin receptor imaging and therapy (37).

There is an urgent clinical need to develop effective systemic treatments in advanced prostate cancer. ${ }^{68} \mathrm{Ga}$-PSMA I\&T will be 
explored as a theranostic that may also apply to other PSMAexpressing malignancies such as pancreatic cancer (38), breast cancer, and primary gliomas (39).

\section{CONCLUSION}

${ }^{68} \mathrm{Ga}$-PSMA I\&T exhibits promising dosimetry and is not associated with any toxicity. It shows favorable imaging characteristics with high lesion-to-background uptake ratios already $30 \mathrm{~min}$ after tracer injection. The best image contrast is achieved $1 \mathrm{~h}$ after intravenous injection. The kidney is the critical organ. Low tracer uptake in normal bone marrow may be of particular interest for future therapeutic applications. Organ-absorbed doses associated with ${ }^{68} \mathrm{Ga}$-PSMA I\&T are lower than those of many other PET radiopharmaceuticals with the exception of the kidneys.

\section{DISCLOSURE}

The costs of publication of this article were defrayed in part by the payment of page charges. Therefore, and solely to indicate this fact, this article is hereby marked "advertisement" in accordance with 18 USC section 1734. Saskia Kropf and Hans-Jürgen Wester are CEOs of Scintomics. No other potential conflict of interest relevant to this article was reported.

\section{ACKNOWLEDGMENT}

We thank Simone Seifert, Simone Groß, Michael SchulzeGlück (members of the nuclear medicine PET team), and Inge Grelle for their support and assistance.

\section{REFERENCES}

1. Siegel RL, Miller KD, Jemal A. Cancer statistics, 2015. CA Cancer J Clin. 2015;65:5-29.

2. Beer AJ, Eiber M, Souvatzoglou M, Schwaiger M, Krause BJ. Radionuclide and hybrid imaging of recurrent prostate cancer. Lancet Oncol. 2011;12:181-191.

3. Schöder H, Herrmann K, Gonen M, et al. 2-[ $\left[{ }^{18} \mathrm{~F}\right]$ fluoro-2-deoxyglucose positron emission tomography for the detection of disease in patients with prostate-specific antigen relapse after radical prostatectomy. Clin Cancer Res. 2005;11:4761-4769.

4. Shiiba M, Ishihara K, Kimura G, et al. Evaluation of primary prostate cancer using ${ }^{11} \mathrm{C}-$-methionine-PET/CT and ${ }^{18}$ F-FDG-PET/CT. Ann Nucl Med. 2012;26:138-145.

5. Nanni C, Schiavina R, Boschi $\mathrm{S}$, et al. Comparison of ${ }^{18} \mathrm{~F}-\mathrm{FACBC}$ and ${ }^{11} \mathrm{C}$-choline $\mathrm{PET} / \mathrm{CT}$ in patients with radically treated prostate cancer and biochemical relapse: preliminary results. Eur J Nucl Med Mol Imaging. 2013;40(suppl 1):S11-S17.

6. Umbehr MH, Muntener M, Hany T, Sulser T, Bachmann LM. The role of ${ }^{11} \mathrm{C}$ choline and ${ }^{18} \mathrm{~F}$-fluorocholine positron emission tomography (PET) and PET/CT in prostate cancer: a systematic review and meta-analysis. Eur Urol. 2013;64:106-117.

7. Mohsen B, Giorgio T, Rasoul ZS, et al. Application of C-11-acetate positronemission tomography (PET) imaging in prostate cancer: systematic review and meta-analysis of the literature. BJU Int. 2013;112:1062-1072.

8. Sweat SD, Pacelli A, Murphy GP, Bostwick DG. Prostate-specific membrane antigen expression is greatest in prostate adenocarcinoma and lymph node metastases. Urology. 1998;52:637-640.

9. Ross JS, Sheehan CE, Fisher HA, et al. Correlation of primary tumor prostatespecific membrane antigen expression with disease recurrence in prostate cancer. Clin Cancer Res. 2003;9:6357-6362.

10. Eder M, Schafer M, Bauder-Wust U, et al. ${ }^{68}$ Ga-complex lipophilicity and the targeting property of a urea-based PSMA inhibitor for PET imaging. Bioconjug Chem. 2012;23:688-697.

11. Afshar-Oromieh A, Zechmann CM, Malcher A, et al. Comparison of PET imaging with a ${ }^{68} \mathrm{Ga}$-labelled PSMA ligand and ${ }^{18} \mathrm{~F}$-choline-based PET/CT for the diagnosis of recurrent prostate cancer. Eur J Nucl Med Mol Imaging. 2014;41:11-20.

12. Afshar-Oromieh A, Haberkorn U, Hadaschik B, et al. PET/MRI with a ${ }^{68} \mathrm{Ga}-$ PSMA ligand for the detection of prostate cancer. Eur J Nucl Med Mol Imaging. 2013;40:1629-1630.

13. Afshar-Oromieh A, Haberkorn U, Eder M, Eisenhut M, Zechmann CM. $\left[{ }^{68} \mathrm{Ga}\right]$ Gallium-labelled PSMA ligand as superior PET tracer for the diagnosis of prostate cancer: comparison with ${ }^{18} \mathrm{~F}-\mathrm{FECH}$. Eur J Nucl Med Mol Imaging. 2012;39:1085-1086

14. Eiber M, Nekolla SG, Maurer T, Weirich G, Wester HJ, Schwaiger M. Ga-PSMA PET/MR with multimodality image analysis for primary prostate cancer. Abdom Imaging. November 21, 2014 [Epub ahead of print].

15. Uprimny C, Kroiss A, Nilica B, et al. Ga-PSMA ligand PET versus F-NaF PET: evaluation of response to Ra therapy in a prostate cancer patient. Eur J Nucl Med Mol Imaging. 2015;42:362-363.

16. Chakraborty PS, Tripathi M, Agarwal KK, Kumar R, Vijay MK, Bal C. Metastatic poorly differentiated prostatic carcinoma with neuroendocrine differentiation: negative on ${ }^{68} \mathrm{Ga}$-PSMA PET/CT. Clin Nucl Med. 2015;40:e163-e166.

17. Demirci E, Ocak M, Kabasakal L, et al. ${ }^{68} \mathrm{Ga}$-PSMA PET/CT imaging of metastatic clear cell renal cell carcinoma. Eur J Nucl Med Mol Imaging. 2014;41:1461-1462.

18. Weineisen M, Schottelius M, Simecek J, Eiber M, Schwaiger M, Wester H. Development and first in human evaluation of PSMA I\&T: a ligand for diagnostic imaging and endoradiotherapy of prostate cancer [abstract]. J Nucl Med. 2014;55:1083.

19. Martin R, Juttler S, Muller M, Wester HJ. Cationic eluate pretreatment for automated synthesis of $\left[{ }^{68} \mathrm{Ga}\right]$ CPCR4.2. Nucl Med Biol. 2014;41:84-89.

20. Boellaard R, Hristova I, Ettinger S, et al. Initial experience with the EANM accreditation procedure of FDG PET/CT devices. Eur J Cancer. 2011;47:S8

21. Lassmann M, Chiesa C, Flux G, Bardies M. EANM Dosimetry Committee guidance document: good practice of clinical dosimetry reporting. Eur J Nucl Med Mol Imaging. 2011;38:192-200.

22. Kletting P, Schimmel S, Kestler HA, et al. Molecular radiotherapy: the NUKFIT software for calculating the time-integrated activity coefficient. Med Phys. 2013;40:102504.

23. Ferrer L, Kraeber-Bodere F, Bodet-Milin C, et al. Three methods assessing red marrow dosimetry in lymphoma patients treated with radioimmunotherapy. Cancer. 2010;116:1093-1100.

24. Forrer F, Krenning EP, Kooij PP, et al. Bone marrow dosimetry in peptide receptor radionuclide therapy with $\left[{ }^{177} \mathrm{Lu}-\mathrm{DOTA}(0), \operatorname{Tyr}(3)\right]$ octreotate. Eur J Nucl Med Mol Imaging. 2009;36:1138-1146.

25. Herrmann K, Lapa C, Wester HJ, et al. Biodistribution and radiation dosimetry for the chemokine receptor CXCR4-targeting probe ${ }^{68}$ Ga-pentixafor. $J$ Nucl Med. 2015;56:410-416.

26. Stabin MG, Sparks RB, Crowe E. OLINDA/EXM: the second-generation personal computer software for internal dose assessment in nuclear medicine. $\mathrm{J} \mathrm{Nucl}$ Med. 2005;46:1023-1027.

27. International Commission on Radiological Protection (ICRP). Publication 60: 1990 recommendations of the International Commission on Radiological Protection. Ann ICRP. 1991;1-201.

28. International Commission on Radiological Protection (ICRP). Publication 89: basic anatomical and physiological data for use in radiological protectionreference values. Ann ICRP. 2002;32:1-278.

29. International Commission on Radiological Protection (ICRP). Publication 103: the 2007 recommendations of the International Commission of Radiological Protection. Ann ICRP. 2007;1-332.

30. International Commission on Radiological Protection (ICRP). Publication 110: adult reference computational phantoms. Ann ICRP. 2009;39.

31. Eberlein U, Broer JH, Vandevoorde C, et al. Biokinetics and dosimetry of commonly used radiopharmaceuticals in diagnostic nuclear medicine: a review. Eur J Nucl Med Mol Imaging. 2011;38:2269-2281.

32. Preylowski V, Schlogl S, Schoenahl F, et al. Is the image quality of I-124-PET impaired by an automatic correction of prompt gammas? PLOS ONE. 2013;8:e71729.

33. Zechmann CM, Afshar-Oromieh A, Armor T, et al. Radiation dosimetry and first therapy results with a ${ }^{124} \mathrm{I} /{ }^{131} \mathrm{I}$-labeled small molecule (MIP-1095) targeting PSMA for prostate cancer therapy. Eur J Nucl Med Mol Imaging. 2014;41:1280-1292.

34. Sandström M, Velikyan I, Garske-Roman U, et al. Comparative biodistribution and radiation dosimetry of ${ }^{68} \mathrm{Ga}$-DOTATOC and ${ }^{68} \mathrm{Ga}$-DOTATATE in patients with neuroendocrine tumors. J Nucl Med. 2013;54:1755-1759.

35. International Commission on Radiological Protection (ICRP). Publication 106: radiation dose to patients from radiopharmaceuticals-addendum 3 to ICRP publication 53. Ann ICRP. 2008;1-197.

36. Barrett JA, Coleman RE, Goldsmith SJ, et al. First-in-man evaluation of 2 highaffinity PSMA-avid small molecules for imaging prostate cancer. $\mathrm{J} \mathrm{Nucl} \mathrm{Med}$. 2013;54:380-387.

37. Werner RA, Bluemel C, Allen-Auerbach MS, Higuchi T, Herrmann K. ${ }^{68} \mathrm{Gal}-$ lium- and ${ }^{90}$ yttrium-/177lutetium: "theranostic twins" for diagnosis and treatment of NETs. Ann Nucl Med. 2015;29:1-7.

38. Ren H, Zhang H, Wang X, Liu J, Yuan Z, Hao J. Prostate-specific membrane antigen as a marker of pancreatic cancer cells. Med Oncol. 2014;31:857.

39. Nomura N, Pastorino S, Jiang P, et al. Prostate specific membrane antigen (PSMA) expression in primary gliomas and breast cancer brain metastases. Cancer Cell Int. 2014;14:26. 